\title{
Transient modelling of heat loading of phase change material for energy storage
}

\author{
W.M. Asyraf ${ }^{1}$, Anusuiah Vasu ${ }^{1}$, Ftwi Y. Hagos $^{1,2,{ }^{*}}$, M. M. Noor ${ }^{1,2}$, Rizalman Mamat ${ }^{1,2}$ \\ ${ }^{1}$ Faculty of Mechanical Engineering, Universiti Malaysia Pahang, 26600 Pekan, Pahang, Malaysia \\ ${ }^{2}$ Automotive Engineering Centre, Universiti Malaysia Pahang, 26600 Pekan, Pahang, Malaysia
}

\begin{abstract}
As the development of solar energy is getting advance from time to time, the concentration solar technology also get the similar attention from the researchers all around the globe. This technology concentrate a large amount of energy into main spot. To collect all the available energy harvest from the solar panel, a thermal energy storage is required to convert the heat energy to one of the purpose such as electrical energy. With the idea of energy storage application that can be narrow down to commercial application such as cooking stove. Using latent heat type energy storage seem to be appropriate with the usage of phase change material (PCM) that can release and absorb heat energy at nearly constant temperature by changing its state. Sodium nitrate $\left(\mathrm{NaNO}_{3}\right)$ and potassium nitrate $\left(\mathrm{KNO}_{3}\right)$ was selected to use as PCM in this project. This paper focus on the heat loading process and the melting process of the PCM in the energy storage using a computer simulation. The model of the energy storage was created as solid three dimensional modelling using computer aided software and the geometry size of it depend on how much it can apply to boil $1 \mathrm{~kg}$ of water in cooking application. The materials used in the tank, heat exchanger and the heat transfer fluid are stainless steel, copper and XCELTHERM MK1, respectively. The analysis was performed using a commercial simulation software in a transient state. The simulation run on different value of velocity but kept controlled under laminar state only, then the relationship of velocity and heat distribution was studied and the melting process of the PCM also has been analyzed. On the effect of heat transfer fluid velocity, the higher the velocity resulted in higher the rate of heat transfer. The comparison between the melting percentages of the PCMs under test conditions show that $\mathrm{NaNO}_{3}$ melts quite faster than $\mathrm{KNO}_{3}$.
\end{abstract}

\section{Introduction}

From day to day, the dependence on fossil fuel energy is quite distressing. Fossil fuel energy will face depletion due to the drastic increase in world energy consumption. The non-renewable energy usage is also one of the leading reasons for the production of greenhouse gases. In recent decades, researchers have been studying the usage of

\footnotetext{
*Corresponding author: ftwi@ump.edu.my
} 
environmental friendly and renewable energy that could be harvested around the globe with no cost $[1,2]$. Solar energy is one of the clean and abundantly available renewable energy resources that can replace the non-renewable energy resources [3]. In the application of solar cooking using concentrated solar power, thermal energy storage (TES) medium is required to store the heat energy obtained from solar energy [4]. Phase change material (PCM) that can store and release heat energy according to necessity by changing its state from solid to liquid or vice versa is likely to be the most suitable type of material that can be used as TES. Heat loading process of the PCM during absorption of heat energy that leads to the phase change from solid to liquid is to be analyzed in this paper.

Lewis et al.[5] have reported that there are three major components needed for solar energy utilization [5]. These include solar capture, conversion, and storage. Solar capture and conversion can be achieved by photo-voltaic cells (PVs). The solar energy utilization and storage are expected to be economical and affordable to enhance its usage. Unfortunately, the cost of material needed to utilize this renewable energy is very expensive compared to fossil fuels usage. There should be an advancement in the approach to utilize this very important sustainable energy in a more economical way. Finding new material for thermal capture during its availability as well as new thermodynamic cycle to harvest the solar energy to produce a useful fuel is necessary. Chwieduk [6] stated that there are two methods of utilizing solar energy available. The first method is indirect utilization method. In this case, renewable energy is used as a secondary effect of solar energy. Hydro energy, ocean energy, and wind energy are the examples of secondary effect of solar energy. These energies are accomplished by photosynthetic processes and is mostly related to biomass and biofuels. The second method is direct utilization of solar energy. In this case, there are two fundamental methods of energy conversion available. These includes photo-thermal conversion of energy and solar - photoelectric conversion of solar energy radiation. The photo-thermal conversion is applied in active low temperature solar water and air heating system, passive low temperature solar water heating, high temperature solar heating system with solar concentrator and electric power system.

Edina Milisic [7] stated that, thermal energy storage must be able to store and release a large amount of energy. Using PCM as a storage medium will completely depend on the latent heat energy for the energy storage system. Unlike sensible heat energy, latent heat type shows less temperature change during energy storage because when the material changes its phase, the combination of pressure and temperature leads to the aggregate state. In the aggregate state, the latent heat will be stored and released almost at constant temperature, thus even a small difference in temperature can be used to store a large amount of latent heat energy. In general, energy storage can be distinguished as sensible heat, latent heat and thermochemical or any combination of it. Atul Sharma et al. [8] investigated about how thermal energy storage works with the change in internal energy of the material. This article includes the sensible heat, latent heat, and thermochemical or any combination of these for further discussion. Sensible heat storage (SHS) is a thermal energy stored by raising the temperature of liquid or solid material. SHS will develop the heat capacity and change in temperature during the loading and unloading processes of heat transfer. The specific heat and temperature change in the storage medium will affect the amount of heat stored in SHS. Another approach is latent heat storage (LHS). In this case, the energy is stored when a material undergoes a change in state that is liquid-to-solid or gas-to-liquid or vice versa. Regin et al. [9] stated that developing a suitable containment for PCM will lead to a better utilization of PCM and heat transfer of fluid. The PCM storage containers with several geometric designs have their own pro and cons. PCM storage container material should meet the requirement of strength, flexibility, thermal stability and corrosion resistance to the PCM material. PCM capsules made of container material of characteristics as above enhance the latent heat storage and at the same time acts as a 
barrier to protect the latent heat storage material from harmful interaction with environment. PCM capsules storage provides sufficient surface for heat transfer and structural stability for easy application.

Agyenim et al. [10] have reported that the most important factors need to be considered in PCM energy storage are the thermal and geometric parameters of the container material required for a fixed quantity of PCM. This criteria has a direct impact to heat transfer characteristic and has major influence to the melting time and performance of the PCM storage unit. The geometric parameters of the PCM container must correspond to the melting time and daily insolation process from a solar collector at specific location in order to ensure long term thermal performance of PCM storage systems. Cabeza et al. [11 15] highlighted a technique to encapsulate the PCM to avoid the liquid phase flow away from the specific location applied. The two principles of PCM encapsulation include microencapsulation and macro-encapsulation. Micro-encapsulation is a small, spherical, rod shaped particle that is covered in a thin, high molecular weight polymeric film. On the other hand, macro-encapsulation comprises the PCM in some form of tube, pouches, sphere or panel that serves directly as heat exchanger.

Arefeh Hesaraki [16] stated that PCM are widely used to store latent heat energy. This is due to PCM's ability to absorb a large amount of heat energy during its change in state at constant temperature. Hence, PCM changes its phase by absorbing or releasing heat energy without much change in temperature. The heat transfer enhancement and performance of the thermal energy system (TES) depends on the thermal conductivity of the PCM. To prevent heat loss, the PCM storage can be insulated but if the heat loss occurs through vaporization of materials, there is no clear method of preventing to avoid it. There are limited study on the high temperature TES employing PCM both experimental and numerical. The effect of heat transfer fluid velocity and fin spacing is conducted for medium temperature application (paraffin wax) by Ogoh and Groulx [17] in a cylindrical heat storage tank and the fins arranged horizontally. The same paraffin wax material is also utilized the study of heat transfer characteristics by Jesumathy et al. [18]. The general objective of this study is to develop a further understanding and modelling of loading process of phase change material (PCM). Therefore the current investigation is narrowed down to these specific objectives of analysis of the heat requirement for solar cooking applications, design and sizing of the thermal energy storage (TES) and execution of a transient simulation on heat energy distribution, heat loading process of thermal energy storage for solar cooking application using phase change material.

\section{Methodology}

Solar cooking model required a solar collector that will absorb the heat and radiation energy from the sun. Then the absorber will transfer the heat energy to the heat transfer fluid (HTF). The heat transfer from the HTF will heat up the PCM in the thermal energy storage (TES). To minimize the heat lost to surrounding the TES should be well insulated. The focus of the current study is only the TES system. The problem definition consists of a thermal heat storage tank with its volume filled by PCM and a heat transfer fluid channel enters at the bottom center of the tank and leaves at the top center of tank. The work is progressed in such a way that the effect of heat transfer fluid in the exchanger tube is studied with different PCMs.

\subsection{Geometry design}

The geometry of thermal energy storage is designed based on the application requirement to boil $1 \mathrm{~kg}$ of pure water. The heat requirement to boil $1 \mathrm{~kg}$ of pure water is calculated in 
order to obtain the minimal volume of PCM needed in the TES. The law of calorimetric to determine heat energy needed to boil $1 \mathrm{~kg}$ of water based on Eq. (1),

$$
Q=c \cdot m\left(100^{\circ} \mathrm{C}-T\right)+\Delta h_{v a p} \cdot m
$$

where, $c=$ specific heat of pure water, $m=$ mass of water, $T=$ initial temperature, and $\Delta h_{v a p}=$ specific enthalpy of vaporization of water. The heat energy calculated when the thermal efficiency of TES is assumed to be $70 \%$ is stated as total energy stored, $E_{\text {stored }}$. Using Eq. (2), the mass and volume of the PCM can be obtain.

$$
m_{P C M, \text { solid }}=\frac{E_{\text {stored }}}{h_{P C M}}, \quad V_{P C M}=\frac{m_{P C M}}{\rho_{P C M}}
$$

The value obtained from Eq. (2) is volume and mass of PCM in room temperature that is in solid state. PCM will change its state to liquid during heat loading process, thus the mass and volume of the PCM in liquid state also need to be considered and can be obtained using Eq. (3) [19].

$$
\rho_{P C M, \text { liquid }}=1000\left[2.112-0.0006891\left(\text { Melting temp }^{\circ} \mathrm{C}\right)\right]
$$

With the help of the above data, dimensional parameters of the TES design can be defined using CAD software. Based on the previous calculation from Eqs. (1) - (3), the volume of the TES should not be less than $0.017 \mathrm{~m}^{3}$. Therefore, the cylindrical shape of TES can be designed using the volume equation given below. The heat transfer formula can yield the parameters such as TES length $l=0.25 \mathrm{~m}$, diameter $=0.3 \mathrm{~m}$ and heat exchanger tube length; $l=0.35 \mathrm{~m}$.

$$
\begin{aligned}
& V_{\text {cylinder }}=\frac{\pi D^{2} L}{4}, V_{\text {pipe }}=\frac{\pi D^{2} L}{4} \\
& Q_{\text {conv }}=h A\left(T_{S}-T_{\infty}\right), A=\pi D
\end{aligned}
$$

where, $h=385 \mathrm{~W} / \mathrm{m}^{2} . K, T_{s}=$ Surface temp ${ }^{\circ} \mathrm{C}, T_{\infty}=$ Surrounding temp $\left({ }^{\circ} \mathrm{C}\right), D=$ $0.015 m$ (diameter of copper tube).

Fig. 1. Complete 3D model of TES with heat exchanger tube.

The geometrical structure considered for the present study is shown in Figure 1. It was created using Solid works modelling software. In this design, minimum dimensions and 
parameters are considered in such a way it can boil only $1 \mathrm{~kg}$ of pure water to make it more simple and economic.

\subsection{Boundary conditions}

The main boundary condition of this experiment excludes any heat flux from other sources except heat from the heat transfer fluid (HTF) in the heat exchanger tube (HET). It was assumed that heat was carried out through the HTF at temperature of 500 to $600^{\circ} \mathrm{C}$. All the walls are treated as adiabatic walls to avoid heat loss. To avoid material transfer between PCM and air, the interface domain is considered as a wall. The initial temperature was set to room temperature. The side wall of HET provide heat flux for HTF. The domain is simplified by cutting it into half by using the symmetry assumption between all four directions. The surface of the tank walls are considered insulated. This can be achieved by applying the heat flux value equals to zero. Located at the bottom of the HET, the HTF flows upwards in the tube. The temperature of HTF is maintained about $350^{\circ} \mathrm{C}$. This is the highest melting point of the PCMs to be tested. The gauge pressure is considered as zero bar for outlet boundary for the temperature output of various rate of flow of HTF in the tube. The initial part of the process is conducted at room temperature and state of the PCM is solid. Stainless steel and pure copper are the metals used for TES and HET respectively. The materials used for $\mathrm{PCM}$ are $\mathrm{KNO}_{3}$ and $\mathrm{NaNO}_{3}$. The mass, momentum and energy equation in the solution are monitored in such way the residuals are converged to a value not more than $10^{-6}$.

\subsection{Governing equation}

In a specific range of temperature, problems in solidification or melting can be solved using FLUENT simulation. FLUENT has the option to track the liquid-solid front explicitly and enthalpy-porosity formulation. In this closed system, the liquid-solid mushy zone or porous zone was neglected due to the fluid material of PCM being fixed in a closed energy storage. Therefore, there is no additional momentum equation added into the simulation. The flow domain is separated into discrete cells and analysis is done by finite volume method. Solving the governing equations are controlled in the point of discrete cells. The partial differential equations were evaluated as algebraic equations using the finite volume method.

The list of differential and algebraic equations can be written as in Eqs. (6) - (14):

Continuity Equation:

$$
\frac{\partial \rho}{\partial t}+\frac{\partial}{\partial x_{j}}\left[\rho u_{j}\right]=0
$$

Momentum Equation:

$$
\frac{\partial}{\partial t}\left(\rho u_{i}\right)+\frac{\partial}{\partial x_{j}}\left[\rho u_{i} u_{j}+p \delta_{i j}-\tau_{j i}\right]=0
$$

Energy Equation:

$$
\frac{\partial}{\partial t}\left(\rho e_{0}\right)+\frac{\partial}{\partial x_{j}}\left[\rho u_{j} e_{0}+u_{j} p+q_{j}-u_{i} \tau_{i j}\right]=0
$$

Stokes law was assumed for mono-atomic gases with Newtonian fluid. Hence, the viscous stress is as follows:

$$
\tau_{i j}=2 \mu S_{i j}
$$

The trace-less viscous strain-rate: 


$$
S_{i j}=\frac{1}{2}\left(\frac{\partial u_{i}}{\partial x_{j}}+\frac{\partial u_{j}}{\partial x_{i}}\right)-\frac{1}{3} \frac{\partial u_{j}}{\partial x_{k}} \delta_{i j}
$$

Fourier's law heat-flux:

$$
q_{j}=-\lambda \frac{\partial T}{\partial x_{j}}=-C_{p} \frac{\mu}{P r} \frac{\partial T}{\partial x_{j}}
$$

Laminar Prandtl number Pr is:

$$
\operatorname{Pr}=\frac{C_{p} \mu}{\lambda}
$$

An equation of state is necessary to close these equations. An ideal gas was assumed so that the following equation to be valid:

$$
\gamma=\frac{C_{p}}{C_{v}}, \quad P=\rho R T, \quad e=C_{v} T, \quad C_{v}-C_{p}=R
$$

where, $C_{v}, C_{p}$ and $\mathrm{R}$ are constant.

Hence the total energy:

$$
e_{0}=e+\frac{U_{k} U_{k}}{2}
$$

\subsection{Numerical simulation}

The 3D geometry is then exported into the simulation commercial computer software. It is used to simulate the mechanism of heat exchange and the melting distribution of PCM. This commercial simulation software provides a step-by-step workspace, so that the analysis cannot be proceeded if the previous step is not complete.

By using a tetrahedral mesh with independent on solid interface, the model is discretized. Solid works file is exported in SAT format to make it easier to edit in Ansys. The setting of Ansys Fluent for numerical solutions are listed in this section. The geometry of the setup has undergone various checks on the mesh through Fluent and the report has appeared in the console. This is done to make sure that the minimum value of the mesh is always positive and the values are selected in the specified range. Once checking the grid of mesh model is done, the required units are selected. The general setting shows the solver settings and discretization details such as equation required for solving the problem and additional physics applications required regarding the solution of the simulation. The Table 1 provides the basic solver settings.

Table 1. Basic solver settings.

\begin{tabular}{|c|c|}
\hline Model & Settings \\
\hline Space & 3D \\
\hline Solver & Pressure based \\
\hline Time & Unsteady, 1st-Order explicit \\
\hline Viscous & Laminar \\
\hline Heat transfer & Enable \\
\hline Solidification and Melting & Enable \\
\hline
\end{tabular}

Solidification and melting is enabled in order to satisfy phase change condition. The value of mushy zone is neglected assuming that the PCM is already in the TES.

The properties of the materials under test are specified including the thermo-physical properties. Stainless steel and copper are the metals used for TES container and heat exchanger tube, respectively. $\mathrm{KNO}_{3}$ and $\mathrm{NaNO}_{3}$ are the PCM materials tested in this work and air is used as forced convection fluid. The settings provide for PCM are given in Table 2. 
Table 2. Thermo-physical properties of major material in the simulation.

\begin{tabular}{|c|c|c|c|c|}
\hline \multirow[t]{2}{*}{ Property } & \multirow[t]{2}{*}{ Units } & \multirow[t]{2}{*}{ Method } & $\mathrm{KNO}_{3}$ & \multirow[t]{2}{*}{$\mathrm{NaNO}_{3}$} \\
\hline & & & & \\
\hline Density & $\mathrm{kg} / \mathrm{m}^{3}$ & $\begin{array}{l}\text { Piecewise } \\
\text { continuous }\end{array}$ & \multicolumn{2}{|c|}{$\rho=2293.6-0.7497 T$} \\
\hline $\begin{array}{c}\text { Specific } \\
\text { Heat }\end{array}$ & $\mathrm{J} / \mathrm{kgK}$ & $\begin{array}{l}\text { Piecewise } \\
\text { continuous }\end{array}$ & \multicolumn{2}{|c|}{$C_{P}=5806-10.833 T+7.2413 \times 10^{-3} T^{2}$} \\
\hline $\begin{array}{c}\text { Thermal } \\
\text { Conductivity }\end{array}$ & $\mathrm{w} / \mathrm{mK}$ & constant & \multicolumn{2}{|c|}{0.5} \\
\hline Viscosity & $\mathrm{kg} / \mathrm{ms}$ & $\begin{array}{l}\text { Piecewise } \\
\text { continuous }\end{array}$ & \multicolumn{2}{|c|}{$\begin{array}{c}\mu=0.4737-2.297 \times 10^{-3}+3.731 \times 10^{-6} T^{2}-2.019 \\
\times 10^{-9} T^{3}\end{array}$} \\
\hline Melting Heat & $\mathrm{kJ} / \mathrm{kg}$ & constant & 116 & 174 \\
\hline $\begin{array}{l}\text { Solidifying } \\
\text { Temperature }\end{array}$ & K & constant & 600 & 573 \\
\hline $\begin{array}{l}\text { Liquefying } \\
\text { Temperature }\end{array}$ & $\bar{K}$ & constant & 610 & 583 \\
\hline
\end{tabular}

XCELTHERM MK1 is a commercial liquid by Radco used as HTF in the heat exchanger tube. The setting and properties of the HTF are given in Table 3.

Table 3.Thermo-physical properties of XCELTHERM MK1 as HTF [2].

\begin{tabular}{|c|c|c|c|}
\hline Property & Units & Method & Value(s) \\
\hline Density & $\mathrm{kg} / \mathrm{m}^{3}$ & constant & 695.3 \\
\hline $\begin{array}{c}\mathrm{C}_{\mathrm{p}} \\
\text { (Specific Heat) }\end{array}$ & $\mathrm{J} / \mathrm{kg}-\mathrm{K}$ & constant & 2.62 \\
\hline Viscosity & $\mathrm{cSt}$ & constant & 0.146 \\
\hline $\begin{array}{c}\text { Thermal } \\
\text { Conductivity }\end{array}$ & $\mathrm{w} / \mathrm{m}-\mathrm{K}$ & constant & 0.076 \\
\hline
\end{tabular}

\section{Results and discussion}

This section discusses the results of the design and simulation using Ansys Fluent software. Besides, It also discusses the trend of the observation and the reason behind it. Simulation results will focus on the heat transfer fluid velocity, type of phase change material that may affect the heat transfer rate of the thermal energy storage tank, and the melting phase distribution of phase change material.

\subsection{Effect of heat transfer fluid velocity}

The simulation of thermal energy storage is assumed to undergo a laminar fluid flow. The heat exchanger tube with diameter of $0.015 \mathrm{~m}$ is used in this work. Heat transfer fluid with density of $695.3 \mathrm{~kg} / \mathrm{m}^{3}$ (based on the online database) and dynamic viscosity of $6.88347 \times$ $10-7 \mathrm{~kg} / \mathrm{m} \cdot \mathrm{s}$ is considered for this experiment [20]. For fluid flow to be laminar, the Reynolds number should be less than 2300, the Reynolds number in this simulation is therefore considered to be 2200 . The highest velocity of the heat transfer fluid at laminar state is about $0.15 \mathrm{~m} / \mathrm{s}$. This is calculated using Reynolds number formula, Eq. (15). The maximum and minimum temperatures of the PCM are calculated at specific time interval of $30 \mathrm{~min}$ for particular fluid velocity. The simulation is carried out for different values of fluid velocities as follows $0.01 \mathrm{~m} / \mathrm{s}, 0.035 \mathrm{~m} / \mathrm{s}, 0.07 \mathrm{~m} / \mathrm{s}, 0.1 \mathrm{~m} / \mathrm{s}, 0.15 \mathrm{~m} / \mathrm{s}$ and $0.2 \mathrm{~m} / \mathrm{s}$ These values of velocities were inserted into the simulation to investigate the relationships. 


$$
R e=\frac{\rho V D}{\mu}
$$

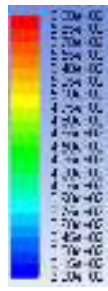

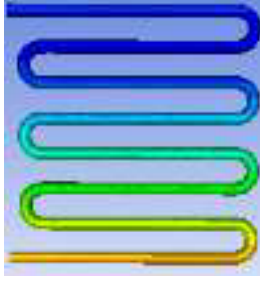

(a)

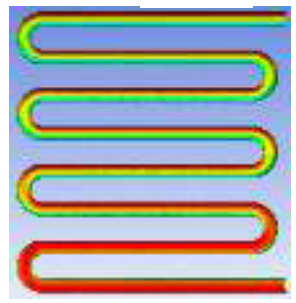

(d)

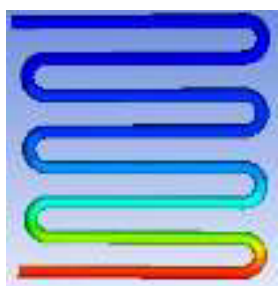

(b)

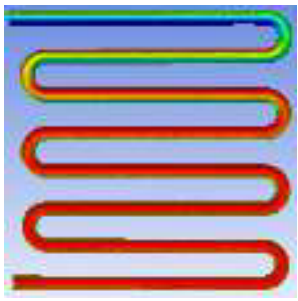

(e)

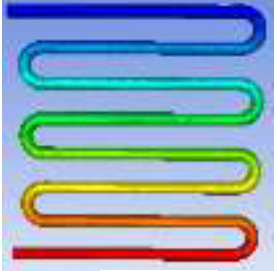

(c)

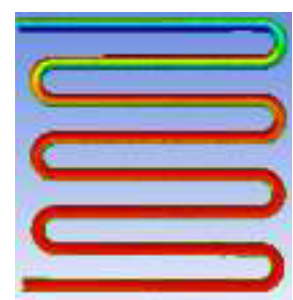

(f)

Fig. 2. Temperature distribution in $\mathrm{K}$ for different heat transfer fluid velocities (a) $0.01 \mathrm{~m} / \mathrm{s}$; (b) 0.035 $\mathrm{m} / \mathrm{s}$; (c) $0.07 \mathrm{~m} / \mathrm{s}$; (d) $0.1 \mathrm{~m} / \mathrm{s}$; (e) $0.15 \mathrm{~m} / \mathrm{s}$; (f) $0.2 \mathrm{~m} / \mathrm{s}$.

The minimum and maximum temperature yields at specific time of $30 \mathrm{~min}$ are $300 \mathrm{~K}$ and $600 \mathrm{~K}$, respectively. The effect of the heat transfer fluid velocity on the temperature of both the heat transfer fluid pipe and on the PCM are depicted in Figures 2 and 3. As shown in Figure 2, the temperature distribution contour is roughly almost the same for both fluid velocities (e) $0.15 \mathrm{~m} / \mathrm{s}$ and (f) $0.2 \mathrm{~m} / \mathrm{s}$. This is probably because, the velocity of heat transfer fluid turns into turbulence state above $0.15 \mathrm{~m} / \mathrm{s}$. As stated earlier, the FLUENT simulation software was set to be in laminar model only, therefore the simulation will not proceed if the heat transfer fluid model enter the turbulence state. The results appeared to be roughly the same because the software will only simulate within laminar stage. The rate of heat transfer is directly proportional to mass flow rate. It also states that mass flow rate is directly proportional to fluid velocity. Thus, it can be accepted that the higher the heat transfer fluid velocity, the higher the rate of heat transfer. This happened because, when the fluid in tube is in high velocity, more new and hot fluid from solar collector flows into the tube that replaces comparatively cooler fluid in the tube. At the end, the temperature of the PCM will be higher as the heat transfer fluid transfers more heat to the PCM. Therefore, the fluid velocity at $0.15 \mathrm{~m} / \mathrm{s}$ should be the optimum velocity for the thermal energy storage tank design.

On the other hand, the temperature of the PCM is observed to be less effected with the heat transfer fluid velocity. The effect is only visible from $0.01-0.035 \mathrm{~m} / \mathrm{s}$. Then if become constant from $0.035-0.2 \mathrm{~m} / \mathrm{s}$. This is in contrary to the report by Ogoh and Groulx [17]. However, the report by Ogoh and Groulx is based on turbulent modeling and with various fin spacing and the PCM is medium temperature heat storage material. Therefore, the model should be extended to the turbulence so that full picture of the simulation could be seen. 


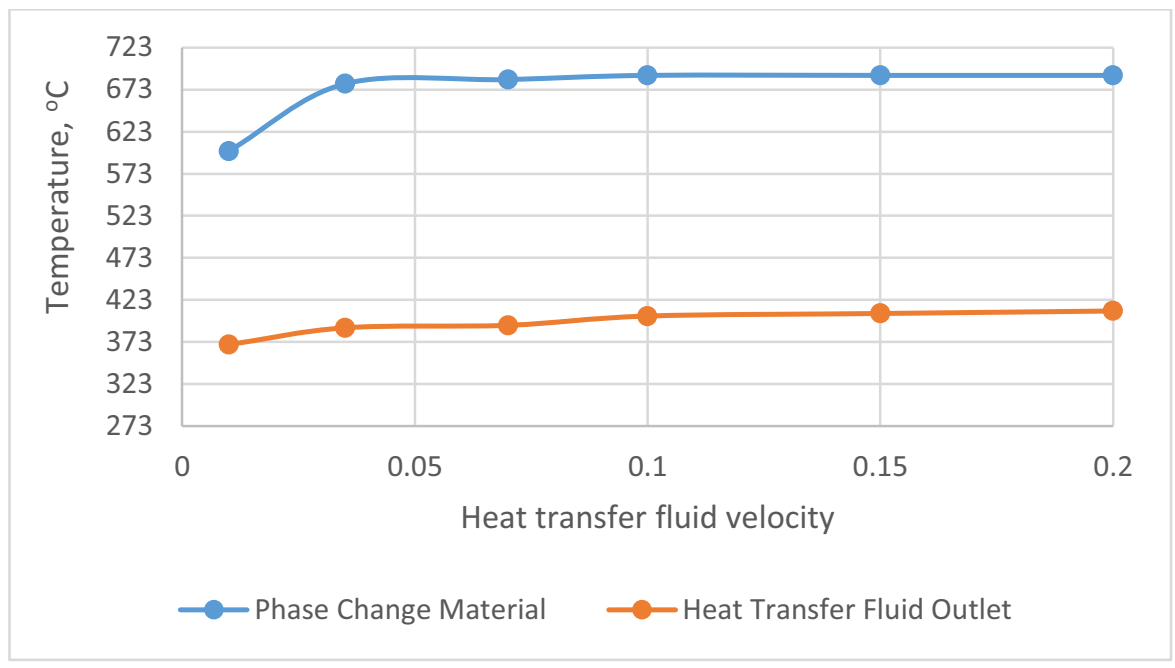

Fig. 3. Effect of heat transfer fluid velocity on the temperatures of the phase change material and the HTF outlet.

\subsection{Effect of phase change material type}

In the current study, the effect of PCM types on the melting rate during the heat charging of the thermal energy storage is investigated by taking sodium nitrate salt $\left(\mathrm{NaNO}_{3}\right)$ and potassium nitrate salt $\left(\mathrm{KNO}_{3}\right)$. These two PCMs are selected to study the effect of temperature for different fluid velocity in HTF. Different types of PCMs have their own physical and thermal properties (Table 2) and those properties decide the rate of temperature distribution during heating process.

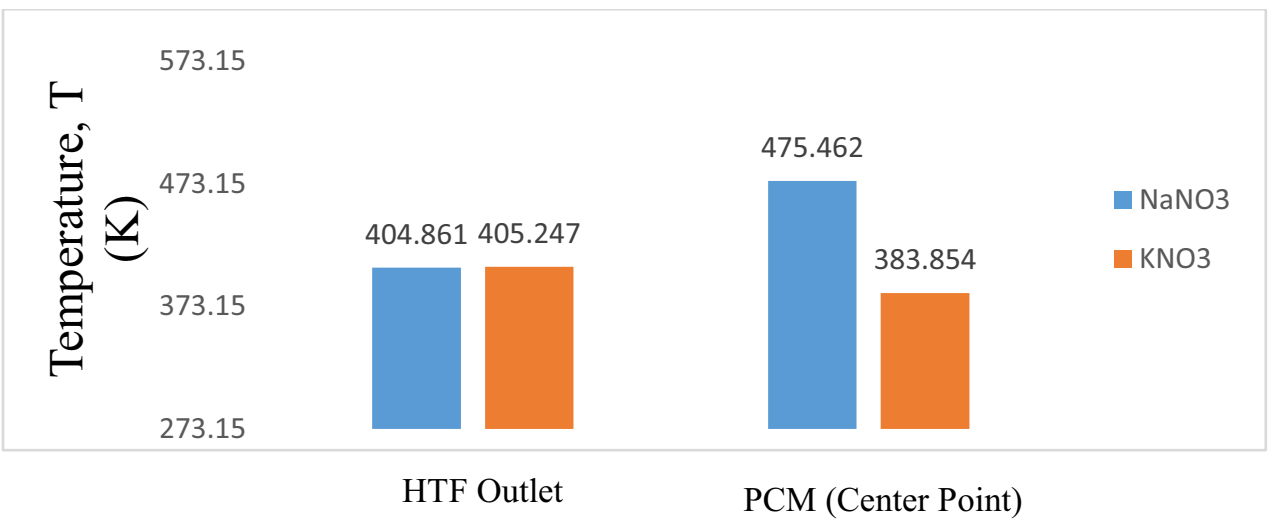

Fig. 4. Temperature of heat transfer fluid and PCM for different types of PCMs.

As shown in Figure 4, the temperature of heat transfer fluid outlet are about the same for both types of PCMs. However, if the analysis focuses on the center point of the PCM temperature, the temperature of the sodium nitrate salt was higher than potassium nitrate salt about $92^{\circ} \mathrm{C}$. This result attributed to the latent heat of the sodium nitrate is higher than potassium nitrate salt. Thus, the sodium nitrate salt is better as compared to potassium nitrate salt to be used as phase change material in this thermal energy storage tank design. 


\subsection{Melting phase rate of PCM}

From the result of simulation, the melting rate of the PCM was investigated. At the room temperature the initial condition of the PCM was solid. Minimum HTF inlet velocity of the laminar flow that has been considered for modelling was the fluid velocity in this case. The simulations provided detailed phase distributions of PCM. The liquid fraction is labelled from the scale 0 (blue contour) to 1 (red contour). In which ' 0 ' indicates the solid state and ' 1 'indicates fully liquid state.

The liquid fraction contour phase distribution is non-uniform in PCM due to very low thermal conductivity and poor heat distribution of HTF in the heat exchanger tube. Heat is distributed non-uniformly along the heat exchanger tube from the bottom (inlet) to the top (outlet). When the temperature at the inlet is higher than the outlet, then the PCM is likely to melt from the inlet level. That is the starting zone of melting process. The conduction of heat transfer is prevailed in the system from the beginning of the process until PCM starts to change its phase. After the PCM starts melting then both heat conduction from HTF and natural convection in the liquid PCM is act in the system. The more progress in melting process is caused by natural convection. So, as the convection process increases then rate of melting also increases.
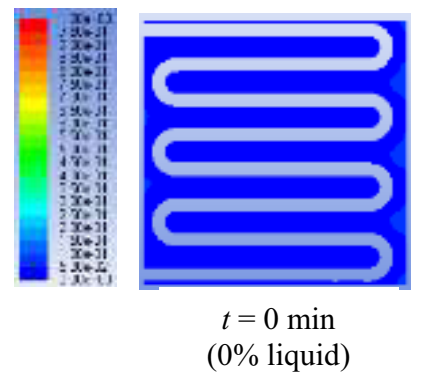

$(0 \%$ liquid $)$

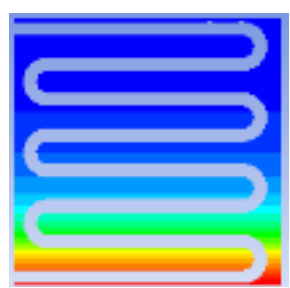

$t=26 \min$

(10\% liquid)

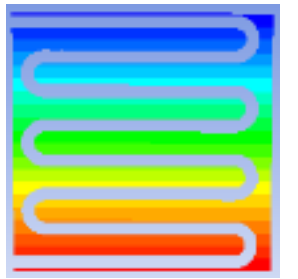

$t=41 \mathrm{~min}$

(23\% liquid)

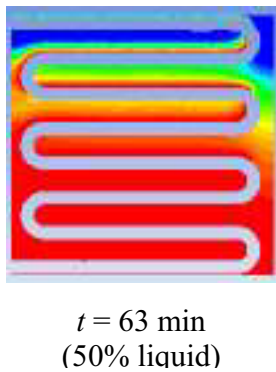

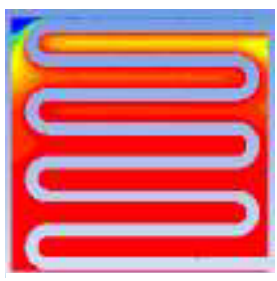

$t=75 \mathrm{~min}$ (85\% liquid)

Fig. 5. Liquid fraction of PCM melting phase distribution.

Figure 5 shows the variation of liquid fraction contour phase distribution with time for $\mathrm{NaNO}_{3}$. The variation of liquid fraction indicates that the PCM is completely solid in the starting point of simulation that is $t=0 \mathrm{~min}$. Thermodynamic properties of the PCM showed variance with time in the simulation setup, hence the PCM starts phase change when having a high heat storage capacity. By comparing the melting phase of PCM with variance of time in Figure 5, it can be observed that the bottom part of PCM is melted easily and quickly but much time is required to melt the PCM that are close to the container wall. This may be attributed to the gravity effect. The contour is seems to be perpendicular to the heat 
exchanger tube wall due to heated moving fluid in it. At $t=63 \mathrm{~min}$, more than $50 \%$ of the PCM is melted. The PCM was melted about more than $85 \%$ when the time reached $t=75$ min, but unfortunately due to the limitation of this simulation, the complete melting phase of PCM seems to be difficult to achieve, Figure 5. Therefore, the final results obtained does not include complete melting state of PCM. Some results displayed in the simulation happens to differ and disturbed due to quality of mesh that can be set under limitation of the simulation software.

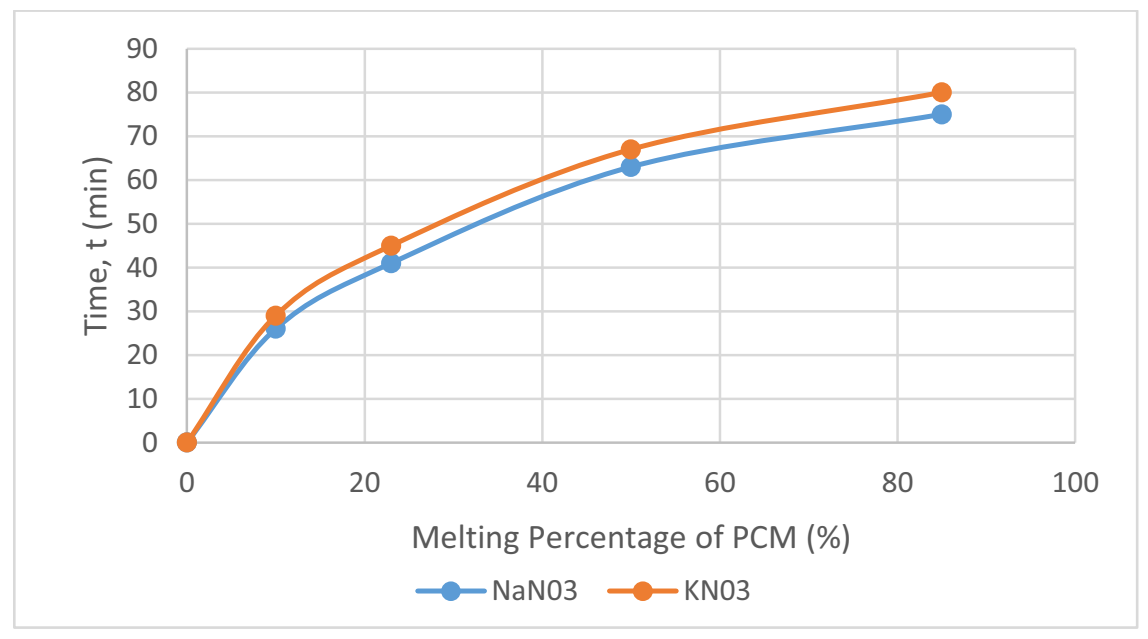

Fig. 6. Time verses PCM Melting rate for both $\mathrm{NaNO}_{3}$ and $\mathrm{KNO}_{3}$.

The comparison between the melting percentages of the PCMs under test show that sodium nitrate melts quite faster than potassium nitrate, Figure 6 . This is because the melting temperature of potassium nitrate $\left(336^{\circ} \mathrm{C}\right)$ is slightly higher than sodium nitrate $\left(308^{\circ} \mathrm{C}\right)$. Sodium nitrate also has a higher latent heat energy compare to potassium nitrate that enable to absorb and store more heat energy. In fact, thermal conductivity of nitrate salt is very low, at the beginning of the simulation, however the melting process takes quite a long time but as the time increase, the PCM will be able to absorb and store more heat energy from the heat exchanger tube because of additional heat transfer from the melted layer of the PCM.

\section{Conclusions}

The PCM usage in medium range heat energy storage have a great potential in solar cooking applications. This work studied and analyzed the relationship between the HTF velocity, type of PCM and PCM heat loading process. Numerical analysis is done by using Ansys Fluent. The characteristics and applications of the PCMs are also included in this study. In this project PCMs are analyzed only during their melting process not in the solidification process (heat unloading process). This work concentrated in studying the time taken by the PCM to distribute temperature. Forced convection of air is included because the PCM is not completely filled up in the tank, thus the presence of air domain is considered in the application continuously. The maximum temperature reached, HTF velocity, melting fraction are computed in unsteady state transient analysis. PCMs of different range of temperatures can be tested in the same way for future usage in many solar applications like water heating etc. 


\section{References}

1. M. Bayray, Mustefa, A., Yohannes, F., Kiros, H., Haileslasie, A., Gebray, P., Hayelom, M., Dagne, A.: Wind energy data analysis and resource mapping of geba catchment, north ethiopia. Wind Engineering 37(4), 333-345 (2013).

2. A.M. Mahmud, Kahsay, M.B., Hailesilasie, A., Hagos, F.Y., Gebray, P., Kelele, H.K., Gebrehiwot, K., Bauer, H., Deckers, S., De Baerdemaeker, J.: Solar Energy Resource Assessment of the Geba Catchment, Energy Procedia 57, 1266-1274 (2014).

3. D.A. Tesfamariam, Kahsay, M.B., Kahsay, M.T., Hagos, F.Y.: Modeling and Experiment of Solar Crop Dryer for Rural Application. Journal of Chemical and Pharmaceutical Sciences (2015).

4. A. Tesfay, Hagos, F., Yohannes, K., Nydal, O., Kahsay, M.: Preparing side charging of PCM storage: theoretical and experimental investigation. In: IOP Conference Series: Materials Science and Engineering 2015, vol. 1, p. 012021. IOP Publishing

5. S.L. Nathan, and Daniel G. Nocera: Powering the planet: Chemical challenges in solar energy utilization. 103(43), 15729-15735 (2006).

6. D. Chwieduk: Solar energy utilisation. Opto-electronics Review 12(1), 13-20 (2004).

7. J.W. Tester: Sustainable Energy: Choosing Among Options. The MIT Press (2005).

8. V.T. Atul Sharma, C. R. Chen, and D. Buddhi: Review on thermal energy storage with phase change material and applications. . Renewable and Sustainable Energy Reviews 13, 318-345 (2009). doi:10.1016/j.rser.2007.10.005

9. S.C.S. A Felix Regin, and J S Saini: Heat transfer characteristics of thermal energy storage system using PCM capsules: A review. Renewable and Sustainable Energy Reviews 12, 2438-2458 ( 2007).

10. N.H. Francis Agyenim, Philip Eames, and Mervyn Smyth A review of materials, heat transfer and phase change problem formulation for latent heat thermal energy storage systems (LHTESS). (2009).

11. L. Cabeza, Roca, J., Noguees, M., Mehling, H., Hiebler, S.: Long term immersion corrosion tests on metal-PCM pairs used for latent heat storage in the 24 to $29^{\circ} \mathrm{C}$ temperature range. Materials and corrosion 56(1), 33-39 (2005).

12. L. Cabeza, Roca, J., Nogués, M., Mehling, H., Hiebler, S.: Immersion corrosion tests on metal-salt hydrate pairs used for latent heat storage in the 48 to $58^{\circ} \mathrm{C}$ temperature range. Materials and Corrosion 53(12), 902-907 (2002).

13. L.F. Cabeza, Castell, A., Barreneche, C., Gracia, A.d., Fernández, A.I.: Materials used as PCM in thermal energy storage in buildings: A review. (2011).

14. L.F. Cabeza, Illa, J., Roca, J., Badia, F., Mehling, H., Hiebler, S., Ziegler, F.: Immersion corrosion tests on metal-salt hydrate pairs used for latent heat storage in the 32 to $36^{\circ} \mathrm{C}$ temperature range. Materials and Corrosion 52, 140-146 (2001).

15. L.F. Cabeza, Svensson, G., Hiebler, S., Mehling, H.: Thermal performance of sodium acetate trihydrate thickened with different materials as phase change energy storage material. Applied Thermal Engineering 23(13), 1697-1704 (2003).

16. A. Hesaraki: CFD modeling of heat charging process in a direct-contact container for mobilized thermal energy storage. MALARDALEN UNIVERSITY SWEDEN (2011)

17. W. Ogoh, Groulx, D.: Effects of the heat transfer fluid velocity on the storage characteristics of a cylindrical latent heat energy storage system: a numerical study. Heat Mass Transfer 48(3), 439-449 (2012). doi:10.1007/s00231-011-0888-3

18. S.P. Jesumathy, Udayakumar, M., Suresh, S.: Heat transfer characteristics in latent heat storage system using paraffin wax. Journal of mechanical science and technology 26(3), 959-965 (2012).

19. U. Ullmann, Tamme, R., Bauer, T., Hahne, E.: Heat storage media. (2013)

20. Radco: Solar Heat transfer Fluids: XCELTHERM MK1 SOLAR. In: Radco (ed.). (2014). 